\title{
A Hybrid Model to Profile and Evaluate Soft Skills of Computing Graduates for Employment
}

\author{
Hemalatha Ramalingam*1, Raja Sher Afgun Usmani*2, \\ Thulasyammal Ramiah Pillai ${ }^{4}$ \\ School of Computer Science and Engineering \\ Taylor's University, Subang Jaya, Malaysia
}

\author{
Ibrahim Abakar Targio Hashem ${ }^{3}$ \\ College of Computing and Informatics \\ Department of Computer Science \\ University of Sharjah, 27272 Sharjah, UAE
}

\begin{abstract}
Emerging tools such as Game Based Assessments have been valuable in talent screening and matching soft skills for job selection. However, these techniques/models are rather stand alone and are unable to provide an objective measure of the effectiveness of their approach leading to mismatch of skills. In this research study, we are proposing a Theoretical Hybrid Model, combining aspects of Artificial Intelligence and Game Based Assessment in profiling, assessing and ranking graduates based on their soft skills. Firstly, an Intelligent Controller is used to extract and classify the graduate skill profile based on data findings extracted using traditional assessment methods of self-evaluation and interview. With motivation and engagement as a competitive difference, an existing Game Based Assessment (OWIWI) is then used to assess the soft skills of these graduates hence generating a Graduate Profile based on results of the game. Moving forward, a ranking technique is then applied to match the profile to selected job requirements based on soft skills required for the job and the graduate strength. Finally, a comparison analysis is concluded based on the soft skills profile obtained before employment (pre-employment) and objective measure feedback of soft skills obtained after employment (post-employment) to provide a validity check to study the effectiveness of the overall Hybrid Model. Specifically, data obtained from this study can be useful in solving issues of unemployment due to mismatch of soft skills at the Higher Learning Institution level.
\end{abstract}

Keywords-Soft skills; artificial intelligence; intelligent controller; game based assessment; graduate profile; hybrid model

\section{INTRODUCTION}

The graduate employment landscape has drastically transformed in recent years. Attributing factors include the emergence of technologically driven process, changing nature of work environments as well as the diversified need of clientele and globalization. Evident to this is the apparent change in Talent Requirement of soft skills which is becoming a crucial priority for long term job success and performance comparatively to hard/technical skills. Soft skills or Human skills as they are sometimes termed, are skills that facilitate the work process of an organization. They are a "set of achievement skills", , understanding and personal attributes that makes individuals more likely to gain employment and to be successful in their chosen occupations. They were once considered as value added but have become an integral component to graduate employability, cutting horizontally across all industries and vertically across all jobs [1]. Soft skills are becoming hard requirements and no longer a 'nice to have' but a 'must have' for graduates. Supporting this is the study conducted by Stanford Research Institute and Carnegie
Melon Foundation involving Fortune 500 CEOs. It revealed that individual soft skills accredit to $75 \%$ of getting and maintaining a job successfully, while only $25 \%$ relies on hard skills or technical knowledge [2].

On the contrary, amongst computing graduates, there is still an obsession on technical skills which creates a false divide that privileges these skills over soft skills. Soft skills are being discounted, dismissed, disappearing and what more, difficult to be assessed and identified. Assessment are used to fit a maximum fit between employee's qualities, the role and the hiring organization. Traditionally, most established assessment methods to evaluate soft skills remain align and well and have been used over a century. Supporting this is conclusive evidence from over 100 years of Industrial Organization (I/O) Psychology together with meta-analyses, support the validity of face to face interviews, personality inventories, assessment centers, 360-feedback ratings, biodata check, situational judgment test, and resume data in extracting and assessing soft skills [3].

Nonetheless, today, with technological advancement and the development of Internet, the prediction of data volume growth to 40 zettabytes in 2020 [4], and the avalanche of size and variety of applications, machines with intelligence algorithms and design methods are required. These new methods are used for filtering, extracting, classifying and assessing data, thus assisting humans in effective decision making in selection of potential talents. Adding to that, with data available via various online platforms, vast amount of human behavior data is generated from digital record consisting of individual preference, values and reputation. Hence, these techniques have become less intuitive, but more data driven, and evidence based.

With motivation, engagement and innovation as a driving factor, the use of Games in assessment has taken a forefront in hiring decisions of many organizations today. Various form of gaming techniques namely Gamification, Game Based Assessment and Serious Games have attracted the attention of Human Resource practitioners. Relying on neuro- science based Artificial Intelligence techniques, these games re-create real world situation disclosing true candidate reactions. A form of stealth assessment, these games are on the rise of adoption as they solve traditional assessment challenges, namely faking and social desirability attainment.

Today, many organizations are engaging third party game assessment tools used in assessing their potential hires for 


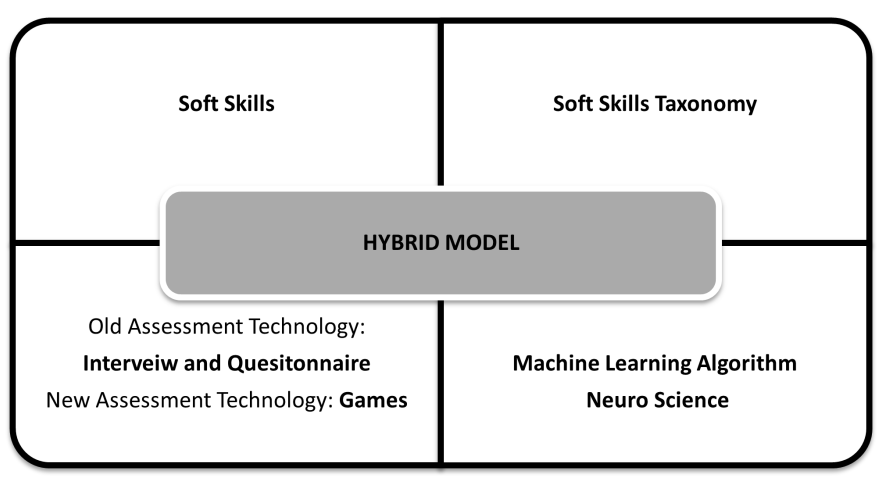

Fig. 1. Hybrid Model - Domain of Coverage.

long term job success. Many of these services and are stand alone and provide high quality data which reveals individual traits, they achieve the intended objective of pre-assessing the relevant soft skills required based on requirements of job roles. However, these new tools and innovations, although having revolutionized the way organizations identify, engage and assess talents, many are stand alone and incomplete in supporting the Human Resource functions of effective talent selection. Furthermore, these assessments fail to justify the validity, effectiveness and value of assessing the candidate's soft skills pre and post-employment. These individual tools and innovations are unable to profile, validate and rank the behavioral traits of candidates, matching the intended skills required for the specified job leading to potential employment.

Present studies incorporating these tools/innovations have not considered the assessment of the validity of traits obtained, verified against the job performance, given a duration of employment. Hence, the purpose of our research is to propose a Theoretical Hybrid Model in filtering, assessing and ranking Computer Graduates soft skills for employment selection. The domains of coverage is as illustrated in Figure 1 above. The objective of this Theoretical Hybrid Model is to propose an improvement in soft skills assessment of graduate selection enabling a effective job match.

\section{LITERATURE REVIEW}

The rise of Artificial Intelligence and automation is changing the job market in the 21 st century. The importance of soft skills amongst employers which identified 10 out of 16 21 st century crucial proficiencies are related to employee soft competencies [5]. There have been many research studies that have provided the definitions and classifications of soft skills. Patacsil and Tablatin terms them as behavioral elements referring to the capability of how individuals perform a job well as well as his/her level of performance [6]. Hurrell, in his research study relates these skills to a vast range of interpersonal and social qualities and competencies which are deemed transferable across economic sections and industries [7]. With reference to employability amongst young graduates as noted by O'Reilly, these skills include Entrepreneurial Skills, which includes the capacity to creatively deal with a given problem, ability to work in teams, learning to learn, effectively communicate with peers and superiors, adaptation to different cultural settings, problem solving, management of conflicts and endurance to deal with complicated or stressful situations enabling them to successfully move from an academic setting to the labor market [8].

Soft skills sets are guided by taxonomies. Various soft skills taxonomies are crucial in employment as well as talent acquisition depending on specific domain of job requirements and industries. In studies of job advertised on four online portals in North America, Europe, Asia and Australia, findings summarized on job title found Communication, Interpersonal, Analytical and Problem Solving and Team Skills to be most critical taxonomies. In a more related research study, a survey concluded by [9] for entry level IS position (graduates), conducted amongst Information Technology global employers, listed Intrapersonal/Interpersonal, Willingness to Learn, Critical Thinking and Attitude as crucial soft skills. A study conducted by [10] noted that the 10 commonly noted soft skills related to jobs in the fields of Business and Computer Technology were Communication, Critical and Decision making, Interpersonal, Negotiation, Problem solving, Self-confidence, Self-management, Team work and Work ethics. On the local front in Malaysia, [11] stated that soft skills that would need to be assessed amongst graduates in Higher Education Institutions for work readiness include Responsibility, Positivity, Time Management, Teamwork, Communication, Leadership, Creative and Innovation. More specific toward this research study of using games in assessing graduate employability [12] elaborated on eight(8) soft skills that seemed to become more and more relevant and prevalent in today's demanding working environment which include Resilience, Adaptability, Flexibility/Willingness to Change and Decision making, Teamwork, Learning Agility, Accountability and Integrity. This skill taxonomy had been adopted to an online Game Based Assessment (OWIWI) deployed by his team which has been tested and deployed.

With reference to soft skills assessments, technological advancements such as Big data, big spatial data [13], Artificial Intelligence and Data Mining techniques have emerged revolutionizing the way organizations identify, develop and engage talents. [14] reported talent assessment in the human resource world is shifting from the traditional methods of assessments to a range of new, novel, efficient tools and techniques for evaluating employee behavior making them less intuitive, more evidence based and data driven. [15] study revealed that with the development in machine learning algorithms, computer based personality judgments are more accurate than those made by humans. Table I lists some of the old and new assessments techniques.

One such novel technique that motivates and engages talents in the area of Human Resource assessment is the use of Games. It is the process of enhancing services with motivational affordance in order to invoke game-full experiences and behavioral outcomes as noted in a research by [16]. [17] further elaborates that, although interactive simulations have been used in assessments and selection methods for decades, efforts have been made to make them more game like hence fun and attractive, thus encouraging/increasing engagement, novelty, competitiveness and visually appeal making it difficult to fake. This can be further supported in a recent study by [18] that reported higher level of process satisfaction, fairness and organizational attractiveness as compared to traditional 
TABle I. Old and New Talent Assessment Methods and Tools

\begin{tabular}{|c|c|c|}
\hline Old Methods & New Tools & Dimension Assessed \\
\hline Interviews & $\begin{array}{l}\text { Digital Interviews } \\
\text { Voice Profiling }\end{array}$ & $\begin{array}{l}\text { Expertise, Social Skills, Motivation } \\
\text { and Intelligence }\end{array}$ \\
\hline $\begin{array}{l}\text { Biodata Supervi- } \\
\text { sory Ratings IQ }\end{array}$ & Big Data & $\begin{array}{l}\text { Past Performance, Current } \\
\text { Performance, Intelligence, Job }\end{array}$ \\
\hline $\begin{array}{l}\text { Situational Judg- } \\
\text { ment Test Self- } \\
\text { Reports }\end{array}$ & Gamification & $\begin{array}{l}\text { Related Knowledge and Big Five } \\
\text { Personality Traits or Minor Traits }\end{array}$ \\
\hline Self-Reports & $\begin{array}{l}\text { Social Media Ana- } \\
\text { lytics }\end{array}$ & $\begin{array}{l}\text { Big Five Personality Traits and Values } \\
\text { (Identity claims) }\end{array}$ \\
\hline Resume & $\begin{array}{ll}\text { Professional Social } \\
\text { Networks }\end{array}$ & $\begin{array}{l}\text { Experience, Past Performance and } \\
\text { Technical Skills and Qualifications }\end{array}$ \\
\hline 360 & $\begin{array}{l}\text { Crowdsourced Rep- } \\
\text { utation/Peer Ratings }\end{array}$ & $\begin{array}{l}\text { Any personality Trait, Competencies } \\
\text { and reputation }\end{array}$ \\
\hline
\end{tabular}

methods. [19] and [20] too reported on the same points as previously and in conclusion positively affects applicant's job pursuit behaviors towards an organization. [21] further reported on game platforms being more realistic upon conducting a research study that measured the effectiveness of using Epistemic Games as a stimulus medium in presenting SJTs. Here is was stated that SJTs connected with other evidence based assessment increases the measurable validity in predicting job performance. In a more related study/findings by [12] reported that converting a SJT (Situational Judgment Test) to an adventure story with game elements confirms the construct validity of the measure of Resilience, Adaptability, Flexibility and Decision Making hence revealing positive results. In his research a fully working game called OWIWI is used which is also currently a readily available Game service provided by the authors. This game is available at www.owiwi.co.uk.

\section{A. Machine Learning Algorithm - Classification Techniques for Skills}

Machine Learning enables machines with algorithms in place to learn and make data driven predictions. The selflearning algorithms such as ANN and its modified forms [22], [23] uses forms of statistics to draw models from large data sets. In the domain of recruitment and selection, Machine Learning Algorithms are used to create patterns from job posts, applicants resume, social media activities and interview response.

In the study done by [24] in employing Machine Learning Technique to classify research's self evaluated questionnaires based on a set of pre-defined soft skills taxonomy for job hire, it was noted that the feature selection task was challenging and the Support Vector Machine (SVM) classifier was the best choice of classifying the skills taxonomy. Support Vector Machine (SVM) type classification technique has been much favorable and has visibly been applied in domains of pattern recognition, face detection and spam filtering as reported in study done by Allahyari [25]. Further findings from survey compiled by [26] on different weighting methods and classification techniques, reported that different techniques perform differently depending on dataset (long and short). A noted finding was a combination of KNN and TF- IDF term weighting scheme performed well in several classification algorithms. Adding to this, more specific to skills sets pertaining to job hire, [27] looked into using Web Scrapping and Machine Learning Technique for classifying skills required for Big Data professions. Job posted online was analyzed and a methodology was proposed. A semi-automated analytical process using AI tools was used to review jobs posted.

\section{B. Adaptive Neuro Fuzzy Inference Systems (ANFIS) used for HR Recruitment and Selection}

Neural Networks is a group of algorithms for machine learning that deals with logic structure of how conclusions will be drawn by humans and is a subset of machine learning. Neuro Fuzzy Inference Systems was introduced by Jang [28] which combines human like reasoning style of Fuzzy Systems with the learning and connectionist structure of Artificial Neural Networks in 1993. Survey findings have noted that, Neuro Fuzzy Inference Systems provide flexible and powerful universal approximations with the ability to explore interpretable IF-THEN rules. The application of Neuro Fuzzy Inference Systems has proliferated and have been evidently applied and developed between the years 2000-2012 covering both social and technological sectors. Applications and domains include medical systems, economic systems, electrical and electronics system, traffic control, student modelling system, image processing and feature extraction, forecasting and predictions, manufacturing and system modelling, enhancements and social sciences.

Adaptive Neural Fuzzy Inference Systems (ANFIS) on the other hand, is a superimposed Fuzzy Inference System over a Neural Layer architecture, in which the Fuzzy Inference Systems learns the training procedure in Neural Network and upon that, behaves exactly as the Neural Network. Notably in various research studies, the most common Adaptive Neural Fuzzy Inference Systems (ANFIS) algorithms is the TagakiSugeno Fuzzy Model. Based on the Literature study surveyed by [29] of Adaptive Neural Fuzzy Inference Systems (ANFIS) applications, it is widely used in the field of diagnostic control, medical research and civil engineering. In another domain, the study concluded by [30] presented a Neuro Fuzzy based methodology to forecast short term stock trends during turbulent stock market periods. The methodology was able to make accurate forecast and results demonstrated solid and superior performance in terms of percentage of forecasting accuracy of stock market trend during crisis.

More specific in the domain of Human Resources, the research concluded by [31], assist HR managers in the assessment of employability of candidates during recruitment process. Here, the employability level of candidates was able to be computed based on three input values of Education, Personal Development and Understanding Power using the Sugeno type inference.

Trailing on, the development of an adaptive information filtering system using Adaptive Neural Fuzzy Inference Systems (ANFIS) was done in the research study concluded by [32]. The procedure of personnel assortment of candidates was automated based on specific Human Resource criterion of skills, vacancies and experience. A model theory was proposed to determine job characteristics defined by experts and record the ranking decisions made. The information obtained was used to provide personalized information filtering system done by analyzing user behavior on web history. Moving more specific to a related research study, [33] focused on creating 
a framework for soft skill profile of jobseekers. Using the Sugeno Fuzzy Inference System, it was aimed at supporting the evaluation of PhD's profiles by calculating the inference rule and selecting the most performing soft skills to be recommended to the HR Manager.

\section{Ranking Technique used for HR Recruitment and Selection}

Analytical Hierarchy Process (AHP) is a Multi Attribute Decision Making (MCDM) model, developed by Saaty [34]. It is a powerful and flexible weighted scoring decision making process to help people set priorities, allowing the selection of the best amongst the alternative based on several conflicting criteria [35]. It has been widely used in industrial practice and academic research to solve multi-criteria decision making [36]. Extending on this, Fuzzy AHP, an analytical extension of AHP, allows for a more accurate description of the decision making process where linguistic variables and Triangular Fuzzy Numbers (TFNs) are used for better consistency and accuracy in decision making as reported in the study done by [35]. Areas of application of this method of problem solving have been concluded in Human Resource Management of personnel recruitment and selection, network pre-negotiation service evaluation, company inventory control and classification, water quality management, selection of measuring instruments for undergraduate engineering institution, hydrogeology groundwater management and measurement of object oriented software usability [35].

More specific, in the domain of Human Resource recruitment, [35] research study applied a combination of Fuzzy AHP, triangular Fuzzy Numbers (TFN) and linguistic variable to improve human expert decision making for recruiting academic staff of University. This study noted that Fuzzy AHP proved to be more useful tool for solving multi-criteria decision problems with inherent uncertainty and deviations in Decision Maker's opinions. In a study conducted by [36], in the automotive industry in Pakistan, the use of AHP for supplier selection based on ranking was proposed as a methodology. There were noted reduction in incoming rejection of suppliers, however aspects of service quality using this technique were difficult to quantify. This led to the consider improved version of AHP, which included Fuzzy AHP and Fuzzy TOPSIS. In another study of ranking potential candidates for selection of human resource conducted by [37], explored the use of Linear Regression and Support Vector Regression. Here, in the job application module, the candidates register and provides a twitter handle and fills an online CV. The emotional aptitude evaluation module estimates the emotional findings by extracting tweets based on the Big Five Personality model. In the grading module, it combines the eligibility criteria from $\mathrm{CV}$ and personality assessment from social handle and assigns a relevance score.

In summary, the digital revolution has transformed Human Resource assessments. No doubt traditional methods in profiling and assessing soft skills remain reliable and valid given many research findings, they have become outdated, mundane, resource and time consuming. Hiring decisions today, are moving towards being more data driven and evidence based. Behaviors are recorded and unprecedented qualities of data are available to quantify human potential given new technologies in Human Resource assessment.
However, these new tools and innovations, although having revolutionized the way organizations identify, engage and assess talents, many are stand alone and incomplete in supporting the Human Resource functions of effective talent selection. Adding to this, these assessments fail to justify the validity, effectiveness and value of assessing the candidate's soft skills pre- and post employment. These individual tools and innovations are unable to profile, validate and rank the behavioral traits of candidates, matching the intended skills required for the specified job leading to potential employment. Present studies incorporating these tools/innovations have not considered the assessment of the validity of traits obtained, verified against the job performance, given a duration of employment. How similar or dissimilar were the traits as compared to before (pre) and after (post) employment? Still in a hypothetical stage due to many empirical unknowns.

\section{RESEARCH FRAMEWORK}

\section{A. Instrument and Dataset}

In relation to this study, purposive sampling technique using a total population sampling will be employed to identify the respondents/informants of the study. The findings from these data will be used to form a judgment analysis based on this sampling techniques. With that, there will be three groups of informants. The first group of informants will be Graduates taking on their Internships from three private Universities in Malaysia, respectively. The Internship timeline varies between 3 and 6 months respective of the individual Universities. The second group of informants will be Academic Supervisors assigned to each internship graduate placement. Individual interviews are conducted with each graduate in evaluating and assessing their soft skills prior to the start date of internship. The final group of information would be the Industry Supervisors of hiring companies assigned to each intern pertaining to their internship roles and responsibilities in the respective companies.

This study is a descriptive research in nature as it seeks to provide accurate descriptions of the characteristics of a graduate in terms of their soft skill traits. With that, a descriptive survey is designed for the Graduates to extract relevant soft skills they possess through experience and their self-evaluated strengths. These questions consist of open ended questions that leads the graduates to reason on the eight(8) given skills addressed in this research study. Feature engineering [38], [39], [40], an important step in data science studies, will be performed on the questionnaire attempted by the Graduates to perform text pre-processing, extraction and classification.

The soft skills used for assessments are based on the eight (8) skills adopted in the Game Based Assessment (OWIWI) and adopted in the study done by [41] and [12]. These soft skills include Resilience, Adaptability, Accountability, Willingness to Change, Decision Making, Integrity, Resilience and Teamwork. Supporting this would be the measure of validity as highlighted in Table II for each skill. Internship graduates have been selected for this study as that there is careful assessment of their performance observed by both the Academic and Industry Supervisor during the three/six month internship period hence feedback can be obtained. With that, the validity and effectiveness of the framework/model can be 
TABLE II. Soft Skills MEASUReS

\begin{tabular}{|c|c|c|}
\hline $\begin{array}{c}\text { Skills } \\
\text { Assessed }\end{array}$ & Definitions & $\begin{array}{l}\text { Construct Validity } \\
\text { Measures }\end{array}$ \\
\hline Resilience. & $\begin{array}{l}\text { The developable capacity to rebound } \\
\text { or bounce back from adversity, con- } \\
\text { flict and failure or even positive } \\
\text { events, progress and increased respon- } \\
\text { sibility [42]. }\end{array}$ & Scale by [43] \\
\hline Adaptability. & $\begin{array}{l}\text { Related to change and how people } \\
\text { deal with it. People's adjustment to } \\
\text { changing environment [44] }\end{array}$ & Scale by [45] \\
\hline $\begin{array}{l}\text { Willingness } \\
\text { to Change }\end{array}$ & $\begin{array}{l}\text { A positive behavioral intention to- } \\
\text { wards the implementation of modifica- } \\
\text { tions in an organization's structure, or } \\
\text { work and administrative processes, re- } \\
\text { sulting in efforts from the organization } \\
\text { member's side to support or enhance } \\
\text { the change process [46] }\end{array}$ & $\begin{array}{l}\text { Scale - HEXACO } \\
\text { Personality } \\
\text { Inventory [47] }\end{array}$ \\
\hline $\begin{array}{l}\text { Decision } \\
\text { Making. }\end{array}$ & $\begin{array}{l}\text { The intellectual process leading to a } \\
\text { response to circumstances through se- } \\
\text { lection among alternatives [48]. }\end{array}$ & [49] \\
\hline Teamwork & $\begin{array}{l}\text { Extent to which a team member is able } \\
\text { to meet the team's output goals, , the } \\
\text { expectations of other members, or its } \\
\text { cost and time objectives [50]. }\end{array}$ & $\begin{array}{ll}\text { Scale - Teamwork } \\
\text { Quality (TWQ ) } \\
{[51]}\end{array}$ \\
\hline $\begin{array}{l}\text { Learning } \\
\text { Agility. }\end{array}$ & $\begin{array}{l}\text { The willingness and ability to learn } \\
\text { new competencies in order to perform } \\
\text { under first-time tough, or different } \\
\text { conditions [52]. }\end{array}$ & $\begin{array}{l}\text { Scale - HEXACO } \\
\text { Personality } \\
\text { Inventory [53] }\end{array}$ \\
\hline Accountability & $\begin{array}{l}\text { Perceived expectation that one's deci- } \\
\text { sions or actions will be evaluated by } \\
\text { a salient audience and that rewards or } \\
\text { sanctions are believed to be congruent } \\
\text { on this expected evaluation [54]. }\end{array}$ & Scale - [55] \\
\hline Integrity. & $\begin{array}{l}\text { It describes a set of beliefs and atti- } \\
\text { tudes and actions reflecting one's per- } \\
\text { sonal values and morals [56]. }\end{array}$ & $\begin{array}{l}\text { Subscale } \\
\text { "morality/ethics", } \\
{[57]}\end{array}$ \\
\hline
\end{tabular}

ascertained given the completion of the internship duration i.e. post-employment.

\section{B. Graduate Profile - (Pre-Employment - Self Evaluation and Interview)}

As depicted in the Proposed Hybrid Model (Fig. 2), to generate a Graduate Soft Skills Profile, input is obtained from both Graduates and Academic Supervisors. Using the advantage of traditional assessment strategies, graduates will attempt a self-evaluation survey of their soft-skills whereby a Machine Learning Algorithm will be used to classify relevant soft skills according to the measures adopted thus generating a Machine Learning (ML) vector of their soft skills. Parallel to this, the Academic Supervisors would interview the graduates assessing all eight soft skills again adopting the same measures of validity consistently. Following this, an Intelligent Based Controller with an Adaptive Neuro Fuzzy Inference System (ANFIS) mechanism will then be used to generate a final Graduate Soft Skills Profile combining both the details of soft skills obtained from the Graduate as well as the Soft Skills Interview results obtained from the Academic Supervisor.

\section{Graduate Profile (Pre-Employment - Game Based Assess- ment)}

As depicted in the Proposed Hybrid Model (Fig. 2), an existing Game Based Assessment called OWIWI will be used to generate the Graduate Soft Skills Profile. Adopting a gamified Situational judgment Test (SJT) using various game mechanics, the players (Graduates) are immersed into a gaming environment assessing the pre-defined eight soft skills. Many trials will await the players assessing these eight skills and the players Situational judgment will be thoroughly tested. Each player will receive eight separate scoring report of each of the eight soft skills. The updated version of OWIWI 2.0 has much improvements which include, a total of eight soft skills, a redesigned User Interface with Progress Bar and Scenario Titles. The soft skills assessed here are skills adopted as the Taxonomy of study for this research study. Following this, the Analytical Hierarchical Process (AHP) methodological approach will be adopted in ranking and decision making of Graduates for selected jobs for recruitment. Upon this, graduates are then classified to hired or not hired for the job. Candidates who are hired are then fit for their Internship tenure. Once the internship is completed, the HR/Industry Supervisor then assess the graduates based on the same eight soft skills providing a Graduate Profile (Post-Employment).

\section{Comparison Analysis (Graduate Profile - Pre-Employment VS Post-Employment)}

A Comparison Analysis is performed to validate the effectiveness of the proposed Hybrid Model. In achieving this, both Pre-Employment Soft Skills Graduate Profile obtained using the traditional method in Section III-B and the Graduate Profile obtained in Section III-C via Game Based Assessment, is compared with the Post-Employment Graduate Profile obtained from the HR/Industry Supervisor upon completion of Internship. The comparison of these profiles would justify the effectiveness of the hybrid model.

\section{Discussion AND CONCLUSION}

The Youth unemployment rate in Malaysia has seen a gradual increase between 2014-2018. Fresh graduate unemployment is an issue in Malaysia with $11.3 \%$ reported amongst Computing graduates. Two main attributing factor on unemployment rates in Malaysia is mismatch of skills, job search and recruitment, and shortage of relevant skills as reported by the Ministry of Education and Department of Statistics Malaysia. Today's workplace, employers want their employees to remain highly skilled and employable. However, based on the Economic Report 2018, employers faced difficulty in finding talent, primarily because of lack of required soft and interpersonal skills as observed in literature study conducted by [58]. The skills gap among graduates is however not limited to Malaysia but is a global phenomenon.

Based on the QS Global Skills Gap in the 21st century report, there is sizable and consistent disparity between employer expectations and student skills based on insights provided by 11,000 employers and 16,000 students across the world. It is noted that subject knowledge skills and technical skills are no longer the determinant factor of employability; however, soft skills are the crucial mechanism for long term job success. With that, Higher Education Institutions (HEI) worldwide are under pressure to produce the right fit among the employable graduates [59].

Nonetheless, although soft skills are extremely valuable and vital, the one thing machines can't replace, assessing them accurately is still an uphill task. Only $41 \%$ of companies have 


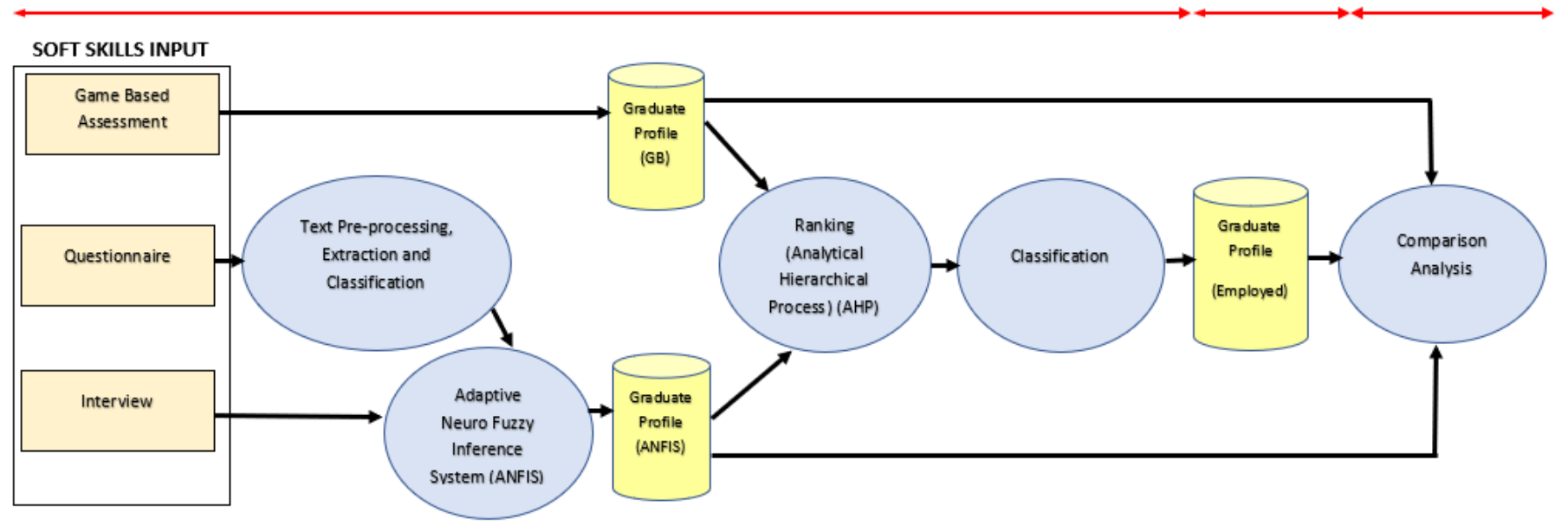

Fig. 2. Hybrid Model.

formal process in place to measure these skills. As noted in the Global Work Trend 2019 report produced by LinkedIn, there is a growing gap between the demands for soft skills and the inability to identify them. No doubt many companies have turned to Artificial Intelligence (AI) powered technological solutions such as games, which are evidence based and data drive to solve this issue, however, much has not been done to assess the validity of these techniques with regards to postemployment performance. This is further supported with many research findings that have deployed games in assessment of soft skills and with an gap of missing objective measures in place to support the validity of such technique.

In solving this gap, this research work aims to explore the proposal of a theoretical hybrid model to profile and evaluate soft skills of computing graduates for employment. The proposed theoretical hybrid model seeks to contribute to an effective mechanism in filtering, assessing, and selecting crucial soft skills amongst graduates thus able to validate the effectiveness of both the traditional assessment techniques as well as the game-based technique. Therefore, in achieving this, this theoretical model proposes a combined assessment of both the traditional assessment strategies of interview and questionnaire as well as an existing game in providing a graduate soft skills profile, respectively. In future work, when implemented, a comparison analysis will be generated between the profile obtained before employment (pre-employment) as well as after employment (post-employment) to justify the validity of the techniques adopted as an objective measure of outcome. Hence, this study is limited to a theoretical proposal and future work will look into implementing the model thus evaluating the effectiveness of this study.

In summary, this model is intended to solve the problems of unemployment amongst graduates, which reportedly among many reasons is caused by mismatch of skills, recruitment, and industry requirement/expectations. This is achieved with the creation of a Graduate Profile, clearer verification of the profile via assessment using Gaming technologies inculcating motivation and engagement as well as ranking them based on these skills with regards to job requirements put forth by the hiring company. Further to this, data obtained from this study can be input provided to respective Higher Learning institution as a support mechanism to look into improving their curricular framework emphasizing the industry need of essential soft skills amongst their graduates for successful employment in the 21 st century.

\section{REFERENCES}

[1] N. H. Omar, A. A. Manaf, R. H. Mohd, A. C. Kassim, and K. A. Aziz, "Graduates' employability skills based on current job demand through electronic advertisement," Asian Social Science, vol. 8, no. 9, p. 103, 2012.

[2] R. S. Malhi, "The hard truth about graduate employability and soft skills," ADEPT: Higher Education Leadership Research Bulletin, vol. 3, pp. 45-56, 2009.

[3] T. Chamorro-Premuzic and A. Furnham, The psychology of personnel selection. Cambridge University Press, 2010.

[4] J. Gantz and D. Reinsel, "The digital universe in 2020: Big data, bigger digital shadows, and biggest growth in the far east," IDC iView: IDC Analyze the future, vol. 2007, no. 2012, pp. 1-16, 2012.

[5] C. Succi and M. Canovi, "Studies in Higher Education Soft skills to enhance graduate employability : comparing students and employers ' perceptions," vol. 5079, 2019.

[6] F. F. Patacsil and C. L. S. Tablatin, "Exploring the importance of soft and hard skills as perceived by it internship students and industry: A gap analysis," Journal of Technology and Science Education, vol. 7, no. 3, pp. 347-368, 2017.

[7] S. A. Hurrell, "Rethinking the soft skills deficit blame game: Employers, skills withdrawal and the reporting of soft skills gaps," Human Relations, vol. 69, no. 3, pp. 605-628, 2016.

[8] J. O'Reilly, W. Eichhorst, A. Gábos, K. Hadjivassiliou, D. Lain, J. Leschke, S. McGuinness, L. M. Kureková, T. Nazio, R. Ortlieb et al., "Five characteristics of youth unemployment in europe: Flexibility, education, migration, family legacies, and eu policy," Sage Open, vol. 5, no. 1, p. 2158244015574962, 2015.

[9] K. Jones, L. N. K. Leonard, G. Lang, K. Jones, L. N. K. Leonard, and G. Lang, "Desired Skills for Entry Level IS Positions : Identification and Assessment Desired Skills for Entry Level IS Positions : Identification and Assessment," vol. 4417, 2018.

[10] A.-M. C. Williams, "Soft skills perceived by students and employers as relevant employability skills," 2015.

[11] I. Abdul, G. Azmi, and R. C. Hashim, "THE EMPLOYABILITY SKILLS OF MALAYSIAN UNIVERSITY STUDENTS," pp. 1-14, 2018. 
[12] I. Nikolaou, K. Georgiou, and V. Kotsasarlidou, "Exploring the relationship of a gamified assessment with performance," The Spanish journal of psychology, vol. 22, 2019.

[13] R. S. A. Usmani, I. A. T. Hashem, T. R. Pillai, A. Saeed, and A. M. Abdullahi, "Geographic information system and big spatial data: A review and challenges," International Journal of Enterprise Information Systems (IJEIS), vol. 16, no. 4, pp. 101-145, 2020.

[14] T. Chamorro-Premuzic, R. Akhtar, D. Winsborough, and R. A. Sherman, "The datafication of talent: how technology is advancing the science of human potential at work," Current Opinion in Behavioral Sciences, vol. 18, pp. 13-16, 2017.

[15] W. Youyou, M. Kosinski, and D. Stillwell, "Computer-based personality judgments are more accurate than those made by humans," Proceedings of the National Academy of Sciences, vol. 112, no. 4, pp. 1036-1040, 2015.

[16] K. Huotari and J. Hamari, "A definition for gamification: anchoring gamification in the service marketing literature," Electronic Markets, vol. 27, no. 1, pp. 21-31, 2017.

[17] M. B. Armstrong, R. N. Landers, and A. B. Collmus, "Gamifying recruitment, selection, training, and performance management: Gamethinking in human resource management," in Emerging research and trends in gamification. IGI Global, 2016, pp. 140-165.

[18] K. Georgiou and I. Nikolaou, "Are applicants in favor of traditional or gamified assessment methods? exploring applicant reactions towards a gamified selection method," Computers in Human Behavior, p. 106356, 2020.

[19] D. S. Chapman and D. Mayers, "Recruitment processes and organizational attraction," in Employee Recruitment, Selection, and Assessment. Psychology Press, 2015, pp. 39-54.

[20] J.-L. McCord, J. L. Harman, and J. Purl, "Game-like personality testing: An emerging mode of personality assessment," Personality and Individual Differences, vol. 143, pp. 95-102, 2019.

[21] S. Rambhatla and D. Gupta, "Effectiveness of epistemic games as a medium to incorporate situational judgement tests," in 2018 IEEE Tenth International Conference on Technology for Education (T4E). IEEE, 2018, pp. 158-161.

[22] A. M. Abdullah, R. S. A. Usmani, T. R. Pillai, I. A. T. Hashem, and M. Marjani, "Prediction of traffic emissions using an optimized artificial neural network (oann) model," International Journal of Advanced Computer Science and Applications, vol. 12, no. 6, 2021.

[23] R. S. A. Usmani, T. R. Pillai, I. A. T. Hashem, M. Marjani, R. Shaharudin, and M. T. Latif, "Air pollution and cardiorespiratory hospitalization, predictive modeling, and analysis using artificial intelligence techniques," Environmental Science and Pollution Research, pp. 1-13, 2021.

[24] A. Azzini, A. Galimberti, S. Marrara, and E. Ratti, "A classifier to identify soft skills in a researcher textual description," in International Conference on the Applications of Evolutionary Computation. Springer, 2018, pp. 538-546.

[25] M. Allahyari, S. Pouriyeh, M. Assefi, S. Safaei, E. D. Trippe, J. B. Gutierrez, and K. Kochut, "A brief survey of text mining: Classification, clustering and extraction techniques," arXiv preprint arXiv:1707.02919, 2017.

[26] A. I. Kadhim, "Survey on supervised machine learning techniques for automatic text classification," Artificial Intelligence Review, vol. 52, no. 1, pp. 273-292, 2019.

[27] A. De Mauro, M. Greco, M. Grimaldi, and P. Ritala, "Human resources for big data professions: A systematic classification of job roles and required skill sets," Information Processing \& Management, vol. 54, no. 5, pp. 807-817, 2018.

[28] C.-T. Sun and J.-S. Jang, "A neuro-fuzzy classifier and its applications," in [Proceedings 1993] Second IEEE International Conference on Fuzzy Systems. IEEE, 1993, pp. 94-98.

[29] Z. J. Viharos and K. B. Kis, "Survey on neuro-fuzzy systems and their applications in technical diagnostics and measurement," Measurement, vol. 67, pp. 126-136, 2015.

[30] G. S. Atsalakis, E. E. Protopapadakis, and K. P. Valavanis, "Stock trend forecasting in turbulent market periods using neuro-fuzzy systems," Operational Research, vol. 16, no. 2, pp. 245-269, 2016.
[31] R. Kumari, V. K. Sharma, and S. Kumar, "Adaptive neural fuzzy inference system for employability assessment," assessment, vol. 3, no. 3, pp. 159-164, 2014.

[32] S. Khan, P. Khodke, and A. Bhagat, "Neuro fuzzy based user queries categorization," in 2015 International Conference on Innovations in Information, Embedded and Communication Systems (ICIIECS). IEEE, 2015, pp. 1-7.

[33] A. Azzini, S. Marrara, and A. Topalovic, "A neuro-fuzzy approach to assess the soft skills profile of a phd," in International Workshop on Fuzzy Logic and Applications. Springer, 2018, pp. 134-147.

[34] T. L. Saaty, "Decision making with the analytic hierarchy process," International journal of services sciences, vol. 1, no. 1, pp. 83-98, 2008.

[35] D. E. Asuquo and F. E. Onuodu, "A fuzzy ahp model for selection of university academic staff," International Journal of Computer Applications, vol. 141, no. 1, pp. 975-8887, 2016.

[36] F. Dweiri, S. Kumar, S. A. Khan, and V. Jain, "Designing an integrated ahp based decision support system for supplier selection in automotive industry," Expert Systems with Applications, vol. 62, pp. 273-283, 2016.

[37] V. M. Menon and H. Rahulnath, "A novel approach to evaluate and rank candidates in a recruitment process by estimating emotional intelligence through social media data," in 2016 International Conference on Next Generation Intelligent Systems (ICNGIS). IEEE, 2016, pp. 1-6.

[38] A. M. Abdullah, R. S. A. Usmani, T. R. Pillai, I. A. T. Hashem, and M. Marjani, "Feature engineering algorithms for traffic dataset," International Journal of Advanced Computer Science and Applications, vol. 12, no. 4, 2021. [Online]. Available: http://dx.doi.org/10.14569/IJACSA.2021.0120435

[39] R. S. A. Usmani, T. R. Pillai, I. A. T. Hashem, N. Z. Jhanjhi, A. Saeed, and A. M. Abdullahi, "A spatial feature engineering algorithm for creating air pollution health datasets," International Journal of Cognitive Computing in Engineering, vol. 1, pp. 98-107, 2020.

[40] R. S. A. Usmani, W. N. F. B. W. Azmi, A. M. Abdullahi, I. A. T. Hashem, and T. R. Pillai, "A novel feature engineering algorithm for air quality datasets," Indonesian Journal of Electrical Engineering and Computer Science, vol. 19, no. 3, pp. 1444-1451, 2020.

[41] K. Georgiou, A. Gouras, and I. Nikolaou, "Gamification in employee selection: The development of a gamified assessment," International Journal of Selection and Assessment, vol. 27, no. 2, pp. 91-103, 2019.

[42] F. Luthans, "The need for and meaning of positive organizational behavior," Journal of Organizational Behavior: The International Journal of Industrial, Occupational and Organizational Psychology and Behavior, vol. 23, no. 6, pp. 695-706, 2002.

[43] G. Wagnild and H. Young, "Development and psychometric evaluation of the resilience scale," Journal of Nursing Management, vol. 1, no. 2, pp. 165-178, 1993.

[44] A. Hamtiaux, C. Houssemand, and P. Vrignaud, "Individual and career adaptability: Comparing models and measures," Journal of Vocational Behavior, vol. 83, no. 2, pp. 130-141, 2013.

[45] A. J. Martin, H. Nejad, S. Colmar, G. A. D. Liem et al., "Adaptability: Conceptual and empirical perspectives on responses to change, novelty and uncertainty," Australian Journal of Guidance and Counselling, vol. 22, no. 1, p. 58, 2012.

[46] E. E. Metselaar, "Assessing the willingness to change," Huispers Vrije Universiteit, Amsterdam, 1997.

[47] M. C. Ashton and K. Lee, "The hexaco-60: A short measure of the major dimensions of personality," Journal of personality assessment, vol. 91, no. 4, pp. 340-345, 2009.

[48] G. D. Nelson, "Assessment of health decision making skills of adolescents." 1984

[49] C. Mincemoyer and D. Perkins, "Assessing youth decision-making skills and influences on decisions," in Forum for family and consumer sciences, vol. 8, no. 1, 2003.

[50] D. G. Ancona and D. F. Caldwell, "Bridging the boundary: External activity and performance in organizational teams," Administrative science quarterly, pp. 634-665, 1992.

[51] N. Meslec and P. L. Curşeu, "Are balanced groups better? belbin roles in collaborative learning groups," Learning and Individual Differences, vol. 39, pp. 81-88, 2015. 
[52] M. M. Lombardo and R. W. Eichinger, "High potentials as high learners," Human Resource Management, vol. 39, no. 4, pp. 321-329, 2000.

[53] K. Lee and M. C. Ashton, "Psychometric properties of the hexaco personality inventory," Multivariate behavioral research, vol. 39, no. 2, pp. 329-358, 2004.

[54] A. T. Hall and G. R. Ferris, "Accountability and extra-role behavior," Employee Responsibilities and Rights Journal, vol. 23, no. 2, pp. 131144, 2011.

[55] N. P. Mero, R. M. Guidice, and S. Werner, "A field study of the antecedents and performance consequences of perceived accountability," Journal of Management, vol. 40, no. 6, pp. 1627-1652, 2014.

[56] J. P. Meriac, D. J. Woehr, and C. Banister, "Generational differences in work ethic: An examination of measurement equivalence across three cohorts," Journal of Business and Psychology, vol. 25, no. 2, pp. 315$324,2010$.

[57] J. P. Meriac, D. J. Woehr, C. A. Gorman, and A. L. Thomas, "Development and validation of a short form for the multidimensional work ethic profile," Journal of Vocational Behavior, vol. 82, no. 3, pp. 155-164, 2013.

[58] N. M. Salleh, J. Mapjabil, and R. Legino, "Graduate work-readiness in malaysia: Challenges, skills and opportunities," in The Transition from Graduation to Work. Springer, 2019, pp. 125-142.

[59] G. Grotkowska, L. Wincenciak, and T. Gajderowicz, "Ivory-tower or market-oriented enterprise: the role of higher education institutions in shaping graduate employability in the domain of science," Higher Education Research \& Development, vol. 34, no. 5, pp. 869-882, 2015. 